\title{
Taller de educación a distancia "Enseñar y aprender Geografía utilizando nuevas tecnologías de la comunicación y de la información"
}

\section{Graciela Cacace*}

Recibido el 3 de marzo de 2014; aceptado el 11 de agosto de 2014

\begin{abstract}
The Education Workshop was developed in 2013. Theoretical and practical training was developed in a virtual classroom platform. The workshop was thought at middlelevel teachers of America. The axis of the workshop was the Information Technology and Communication from the particular look of Geography Science.
\end{abstract}

Key words: Geography, GIS, TICs, Virtual learning.

\section{Resumo}

Durante o ano de 2013 se desenvolveu a Oficina de educação a distância como uma proposta de capacitação teórico-prática desenvolvida totalmente em plataforma virtual. Foi dirigida a professores de nível médio da América. O eixo da Oficina foi constituído pela Tecnologia da Informação e Comunicação a partir do olhar particular de Geografia.

Palavras-chave: Geografia, GIS, TICs, educação virtual.

\section{Resumen}

Durante el año 2013 se desarrolló un taller de educación a distancia, como una propuesta de capacitación teórico-práctica desarrollado íntegramente en una plataforma aula virtual. Destinado a docentes de nivel medio de América, el eje del taller lo constituyeron las Tecnologías de la Información y la Comunicación desde la mirada particular de la Geografía.

Palabras clave: Geografía, SIG, TICs, enseñanza virtual.

* Licenciada, profesora, Universidad Nacional de Luján, República Argentina, correo electrónico: cacacegraciela@gmail.com 


\section{Introducción}

Durante el año 2013 se desarrolló el Taller de educación a distancia "Enseñar y aprender Geografía utilizando nuevas tecnologías de la comunicación y de la información”, que tuve la oportunidad de dirigir con la participación del Instituto Geográfico Nacional (IGN) y la Academia Nacional de Geografía de Argentina. El Instituto Panamericano de Geografía e Historia (IPGH) brindó el marco formal, lo difundió en el ámbito panamericano y brindó el apoyo que exige el proyecto.

El Taller fue una propuesta de capacitación teórico-práctica autoasistida, desarrollado en una plataforma de e-learning (aula virtual) y destinado a docentes de nivel medio, hispanohablantes de América. El eje del Taller lo constituyeron las tecnologías de la información y la comunicación desde la mirada particular de la Geografía.

El objetivo principal de la capacitación, fue otorgar a los docentes herramientas didácticas que les permitan generar y desarrollar prácticas de enseñanza innovadoras a partir del uso de información espacial.

\section{Un marco conceptual para el Taller}

\section{La Geografía como ciencia}

La Geografía ocupa una posición destacada como ciencia de la organización del territorio, que estudia la diferenciación de espacios sobre la superficie terrestre y que puede modelar pautas de distribución espacial. Todo espacio geográfico es un lugar natural habitado, modificado y organizado por las sociedades de acuerdo con las actividades económicas y culturales que allí se desarrollan. Posee diferentes escalas de análisis que van desde lo global a lo local. El espacio geográfico es el objeto de estudio de la Geografía.

Definir a la Geografía como ciencia implica considerar un cuerpo de conocimientos racionales, sistemáticos, organizados, verificables, falibles (Bunge, 1981) que fueron adquiridos por un método específico y que buscan establecer regularidades y generalidades respecto de las manifestaciones espaciales de la relación entre sociedades y su ambiente. Estas generalidades permiten llegar a explicar y predecir patrones de localización, distribución, asociación, interacción y evolución de fenómenos sobre el territorio (Buzai y Baxendale, 2006).

Es un conocimiento racional porque es producto de la razón, se rige principalmente por aspectos lógicos en la construcción de conocimiento. Es sistemático, es un conocimiento que sigue ciertas reglas para su formulación, tiende a ser exacto porque busca la correspondencia entre enunciados y la realidad, puede verificarse y contrastar hipótesis. En este sentido cabe destacar que, como afirma el doctor G. Buzai "la verdad, en ciencia, siempre es provisoria". 
La Geografía como ciencia de la organización del territorio, implica considerarla como ciencia aplicada o aplicable donde los conocimientos obtenidos en investigaciones puras se utilizan o pueden aplicarse y ser útiles para la sociedad, en tanto son conocimientos concernientes a problemas prácticos y a las acciones mediante las cuales podemos fabricar objetos o cambiar la naturaleza que los circunda (Klimovsky, 1995).

La Geografía es la ciencia del análisis espacial y territorial donde interactúan la naturaleza y la sociedad. Por eso enseñar geografía tiene un alto valor pedagógico. Los problemas territoriales son de interés social y entenderlos facilita la comprensión de la compleja trama de la organización y reorganización permanente de los espacios y territorios en diversas escalas. La geografía permite al estudiante ubicarse espacialmente. Es necesario desterrar la idea de la geografía como inventario y enseñar a pensar el territorio de y para la sociedad.

Se necesitan entonces enfoques didácticos que propongan visiones integrales, que respondan a preguntas centrales de la geografía como qué, cómo, dónde y por qué los factores, objetos, actores y sus relaciones-interacciones tienen una determinada expresión en el espacio y en el tiempo (Chiozza y Carballo, 2006). Podemos considerar entonces que las manifestaciones espaciales son respectivamente objeto de estudio y objetivo final de los análisis en geografía. Difícilmente hacemos geografía si carecemos de manifestaciones espaciales, de un territorio dado y si no realizamos un análisis de él, donde se integran y sintetizan diferentes variables (Buzai y Baxendale, 2006). Esta síntesis puede considerarse uno de los principios de la geografía (Vilá Valentí, 1983).

No todas las sociedades actúan de la misma forma frente al medio natural. Con el paso del tiempo, las sociedades evolucionan, sufren cambios y esos cambios se observan también en el modo de organizar el espacio. Cada etapa histórica, cada sociedad y cada modo de producción tienen una lógica espacial. Día tras día, la sociedad insiste en la búsqueda de nuevos escenarios socio-económicos. Hoy el dominio de las sociedades sobre la naturaleza es casi total: ya no quedan lugares del planeta donde no se encuentre presencia humana. Todos los ambientes, de una manera u otra, en menor o mayor medida, están "socializados".

La geografía ha desarrollado a lo largo de su historia diferentes maneras de ver y analizar la realidad. Cambios revolucionarios en la historia de la humanidad permitieron la aparición de diferentes visiones que demuestran que la Geografía es una ciencia en constante evolución. Esas diferentes maneras de ver y analizar la realidad conviven sin que una de ellas llegue a desplazar y reemplazar completamente a la anterior: la Geografía Regional, la Geografía Racionalista, la Geografía Cuantitativa, la Geografía Radical que incluye a la Geografía Crítica y la Geografía Humanista. 
Desde la década de los ochenta, la Geografía ha comenzado a perfilar diversas líneas de estudio, desarrollando nuevos campos de conocimiento, revalorizando posturas paradigmáticas, ampliando sus especialidades al dirigirse hacia relaciones interdisciplinarias en el análisis de la realidad. Las perspectivas actuales son tres: la Ecología del Paisaje (Naveh y Lieberman, 1984), la Geografía Posmoderna (Soja, 1989) y la Geografía Automatizada (Dobson, 1983) basada en la Geotecnología. La Ecología del Paisaje incorpora conceptos de la Geografía Regional, Racional y Humanística. Se basa en perspectivas clásicas con aporte sistémico del cuantitativismo revalorizando la Geografía Física vinculada al importante peso adquirido por la dimensión ambiental en Geografía. La Ecología del Paisaje busca superar la dicotomía sociedad-naturaleza basándose en el concepto de Geosistema (Baxendale, 2010). La Geografía Posmoderna incorpora conceptos de la Geografía Crítica. Intenta rescatar el papel central de la dimensión espacial de la Geografía Crítica. La Geografía Automatizada o Geotecnología se sustenta en la Geografía Racionalista y en la Geografía Cuantitativa. Desde un punto de vista disciplinario, la Geografía Automatizada brinda nuevos horizontes a partir de la revalorización de sus aplicaciones en el ambiente computacional en el que la realidad se transforma en un modelo digital. La herramienta teórico-metodológica fundamental de la Geografía Automatizada o Geotecnológica la constituyen los Sistemas de Información Geográfica (SIG). El uso de los SIG se basa en conceptos de neta naturaleza espacial como la localización, distribución y evolución espacial (Buzai, 2008). Los Sistemas de Información Geográfica han producido una innegable revolución tecnológica, pero principalmente una notable revolución intelectual. La primera se encuentra estrechamente relacionada con los métodos y técnicas que se han estandarizado para entender los modos de organización del espacio geográfico y actuar en el análisis espacial centrado en la gestión y planificación del territorio. La segunda se encuentra vinculada a la forma en la que se puede pensar la realidad, es decir, la base empírica en la cual el ser humano ha desarrollado sus diversas actividades en el planeta.

Con el inicio del siglo XXI la dimensión espacial ha cobrado particular importancia al momento de analizar y comprender el mundo que nos rodea. El desarrollo tecnológico actual ha posibilitado la aparición de las denominadas Tecnologías de la Información y las Comunicaciones (TICs) que llevan a configurar el marco de vínculos globales basados en el formato digital, en el cual la tecnología de los SIG ocupa una posición destacada. En este contexto, la Geografía se hace global cuando a través de los Sistemas de Información Geográfica se difunde una visión espacial al resto de las ciencias reforzando su carácter interdisciplinario. La Geografía Global ha sido un camino inevitable en el que Geografía Automatizada impacta en el resto de las ciencias. Finalmente, el camino transdisciplinario establece una necesidad extra geográfica: aparecen como nuevas disciplinas las Ciencias de la información geográfica, y las Ciencias sociales integradas espacialmente, la primera con mayor orientación 
hacia la técnica y la segunda más teórica, aunque ambas generando nuevos cuerpos de conocimiento pero centrados en conceptos de naturaleza espacial (Buzai, 2008).

\section{Las sociedades del conocimiento}

Desde mediados del siglo XX, los grandes cambios provocados por la tercera revolución industrial - la incorporación de las nuevas tecnologías - han creado una nueva dinámica social que se encuentra en constante evolución. El nuevo "salto tecnológico" (leap frogging) que incluye el auge de Internet, la telefonía móvil, las tecnologías digitales, abre nuevas posibilidades al desarrollo. Las aplicaciones computacionales se han instalado definitivamente en el ámbito de las ciencias y han tomado una posición central en la mayoría de las actividades humanas. El desarrollo tecnológico actual ha posibilitado la aparición de las denominadas Tecnologías de la Información y las Comunicaciones (TICs) que llevan a configurar el marco de vínculos globales basados en el formato digital.

En este contexto, el conocimiento se ha convertido en objeto de inmensos desafíos económicos, políticos y culturales. Hoy formamos parte de las sociedades del conocimiento y de la información. ${ }^{1}$ El concepto de sociedad de la información se basa en los progresos tecnológicos. En cambio, el concepto de sociedades del conocimiento comprende dimensiones sociales, éticas y políticas mucho más profundas.

La revolución de las nuevas tecnologías ha significado la entrada de la información y del conocimiento en una lógica acumulativa que Manuel Castells ha definido como "la aplicación [del conocimiento y la información] a los procedimientos de creación, procesamiento y difusión de la información en un bucle de retroacción acumulativa entre la innovación y sus utilizaciones prácticas”. La información es efectivamente un instrumento del conocimiento, pero no es el conocimiento en sí. Pese a que estamos presenciando el advenimiento de una sociedad mundial de la información, en la que la tecnología ha superado todas las previsiones con respecto al aumento de la cantidad de información disponible y la velocidad de su transmisión, todavía nos queda un largo camino que recorrer para acceder a auténticas sociedades del conocimiento. El exceso de información no es necesariamente una fuente de mayor conocimiento. La reflexión sobre las sociedades del conocimiento permite replantearse el concepto de desarrollo. Entramos en una era en la que para existir, sobrevivir y no quedar al margen, es necesario comunicar cada vez más, y sobre todo cada vez más deprisa.

1 La noción de "sociedad del conocimiento" fue utilizada por primera vez en 1969 por un universitario, Peter Drucker, y en la década de los noventa fue profundizada en una serie de estudios detallados publicados por investigadores como Robin Mansell o Nico Stehr. Esta noción nació a finales de los sesenta y principios de los setenta, casi al mismo tiempo que los conceptos de "sociedades del aprendizaje" y de educación para todos a lo largo de toda la vida. 
La interactividad es otra característica de estos nuevos soportes del conocimiento. A este respecto, conviene efectuar una distinción entre los media "de sentido único" como la radio, la televisión o la prensa que efectúan una comunicación centralizada, desde una fuente a un público, y los media "interactivos" como el teléfono, que permite mantener a distancia un auténtico diálogo "cara a cara", o Internet, que ofrece no sólo una interconexión inmediata e interfaces multimedia, sino también la posibilidad de que las organizaciones o los individuos conectados interactúen en tiempo real.

El ritmo constante de la innovación tecnológica obliga a efectuar actualizaciones periódicas. Estamos en presencia de un verdadero determinismo tecnológico. El acceso a Internet a alta velocidad, las pantallas interactivas en los teléfonos móviles, PC, pizarras y la comercialización de nuevos programas informáticos, al reducir considerablemente el costo de las comunicaciones telefónicas, están modificando completamente las bases del debate sobre el acceso a las tecnologías y a contenidos diversificados.

Una de las características más importantes de las sociedades del conocimiento es propiciar la educación para todos a lo largo de toda la vida. Se supone que una sociedad del conocimiento ha de poder integrar a cada uno de sus miembros y promover nuevas formas de solidaridad con las generaciones presentes y venideras. No deberían existir marginados en las sociedades del conocimiento, ya que éste es un bien público que ha de estar a disposición de todos. Sin embargo, ya podemos observar cómo se multiplican paradójicamente las brechas y las exclusiones, tanto entre los países como dentro de cada sociedad. Vivimos en una sociedad en la que el $20 \%$ de la población mundial concentra en sus manos el $80 \%$ de los ingresos del planeta. ${ }^{2}$ Las brechas digitales son un problema muy preocupante. La exclusión de la información no sólo es una cuestión de acceso y conexión, sino también de contenidos y guarda relación con los obstáculos educativos, culturales y lingüísticos que hacen de Internet un objeto extraño e inaccesible para las poblaciones que han quedado confinadas en los márgenes de la mundialización.

Se suele hablar de sociedad mundial de la información y de una red extendida por todo el mundo (World Wide Web), pero en realidad sólo el 40\% de la población mundial tiene acceso a diario a Internet en su hogar o trabajo y en su telefonía móvil. ${ }^{3} \mathrm{El}$ 90\% de las personas "conectadas" viven en los países industrializados: 30\% en América del Norte, 30\% en Europa, 30\% en Asia y el Pacífico y el 10\% en América Latina. Esta "brecha digital" es ante todo un problema de acceso a las infraestructuras. A este respecto, conviene recordar que 2,000 millones de seres humanos no disponen de corriente eléctrica, que por el momento es la condición básica del acceso masivo a

Programa de Naciones Unidas para el Desarrollo (PNUD) 2013.

UIT (Unión Internacional de Telecomunicaciones), Naciones Unidas para las Tecnologías de la Información y la Comunicación — TIC, 2013. 
las nuevas tecnologías. La brecha digital alimenta otra mucho más preocupante: la brecha cognitiva, que acumula los efectos de las distintas brechas observadas en los principales ámbitos constitutivos del conocimiento —el acceso a la información, la educación, la investigación científica y la diversidad cultural y lingüística- y representa el verdadero desafío de las sociedades del conocimiento. La resolución del problema de la brecha digital no bastará para resolver el de la brecha cognitiva. En efecto, el acceso a los conocimientos útiles y pertinentes no es una mera cuestión de infraestructuras, sino que depende de la formación, de las capacidades cognitivas y de una reglamentación adecuada sobre el acceso a los contenidos. Poner en contacto a las poblaciones mediante cables y fibras ópticas no es suficiente, pues esa "conexión" debe ir acompañada por creación de capacidades y la producción de contenidos adecuados. Las tecnologías de la información y la comunicación necesitan aún que se elaboren nuevos instrumentos cognitivos para actualizar todo su potencial.

Las sociedades del conocimiento nos llevan a otro concepto, las sociedades del aprendizaje. Desde los trabajos realizados por Robert Hutchins (1968) y Torsten Husén (1974), la expresión "sociedad del aprendizaje" (learning society) se refiere a un nuevo tipo de sociedad en la que la adquisición de los conocimientos no está confinada en las instituciones educativas (en el espacio), ni se limita a la formación inicial (en el tiempo). En un mundo cada vez más complejo en el que todo individuo puede verse obligado a ejercer varias profesiones en el transcurso de su existencia, es indispensable seguir aprendiendo a lo largo de toda la vida.

Las mutaciones en el plano pedagógico y educativo, con un claro desplazamiento del interés por los poseedores del saber hacia los que tratan de adquirirlo, no sólo en el marco de los sistemas formales de educación, sino también en las actividades profesionales y la educación informal, en la que desempeñan un papel tan importante la prensa y los medios audiovisuales. Este modelo de aprendizaje se ha difundido mucho más allá del universo de los educadores y se ha extendido a todos los niveles de la vida económica y social.

Frente a las mutaciones cada vez más rápidas, se cuestionan los antiguos modelos y cobra una importancia creciente el "aprender haciendo" (learning by doing), la capacidad para innovar y la dinámica cognitiva. Este modelo del aprendizaje se ha difundido mucho más allá del universo de los educadores y ha penetrado en todos los campos de la vida económica y social.

Aprender a aprender sigue siendo para el alumno la mejor garantía de que podrá después proseguir su itinerario educativo en estructuras formales o no formales. Una de las competencias necesarias para aprender a aprender, es la capacidad para buscar, jerarquizar y organizar la información que encontramos, principalmente - aunque no exclusivamente - en Internet. Hacer que un estudiante aprenda a aprender es ponerlo delante de una computadora, no para hacer de ella un mero usuario, sino para enseñarle a que se sirva de ese instrumento y lo adapte a sus usos y su cultura. El dominio 
de la lectura y el dominio del soporte digital no se excluyen sino que se complementan. En las sociedades del conocimiento el aprendizaje es continuo.

Las nuevas tecnologías abren paso a una educación basada en el desarrollo del aprendizaje electrónico (e -learning) o "E-ducación". Este concepto encierra desde el trabajo en una PC en las aulas hasta las carreras cursadas totalmente a distancia. La enseñanza virtual permite una supervisión individualizada, unida a una flexibilidad de la gestión del aprendizaje y a una mayor autonomía en la adquisición del saber. Más allá de las ofertas educativas institucionales, Internet tiende a convertirse en el medio privilegiado de la autodidáctica, suministrando instrumentos de aprendizaje informal.

El derecho a la educación es uno de los derechos humanos proclamados en la Declaración Universal de Derechos Humanos (1948). La educación básica para todos sigue siendo una prioridad absoluta. Pero hoy se propicia una educación para todos y a lo largo de toda la vida. En este marco, ha adquirido una gran importancia la educación de los adultos como una respuesta a la creciente inestabilidad del empleo y los oficios y carreras profesionales. El ser humano ocupa un lugar esencial en la adquisición y comunicación permanentes de los conocimientos. El fenómeno del aprendizaje (learning) está destinado a generalizarse en nuestras sociedades a todos los niveles. Con la noción de educación para todos a lo largo de toda la vida, educación ya no es sinónimo de escolaridad. En la mayoría de los sistemas educativos la educación básica se imparte durante la escolarización obligatoria.

Puede afirmarse que la escuela, en tanto que lugar e institución, seguirá siendo por mucho tiempo el pilar fundamental de este tipo de educación y continuará asumiendo la misión fundamental de la alfabetización.

\section{Las TICs como herramientas didácticas en el aula}

Las sociedades de la información y del conocimiento están planteando nuevas formas de comunicación, de construcción del conocimiento y de convivencia. Esta realidad nos obliga a analizar la mejor forma de integrar las nuevas tecnologías a las propuestas de enseñanza. Ello supone utilizar nuevos materiales didácticos fundamentados pedagógicamente. Cabrero Almenara (1999) señala que los materiales didácticos propician el desarrollo de habilidades cognitivas, en un contexto determinado, facilitando y estimulando la intervención mediada sobre la realidad. La tecnología educativa se ocupa de descubrir la potencialidad educativa de los medios y materiales diversos y la incorporación de los mismos a las instituciones educativas.

Las TICs son potenciadores de habilidades intelectuales de los alumnos y son un vehículo expresivo para comunicar ideas, sentimientos, opiniones y favorecer el aprendizaje. Antes, el papel de los formadores era enseñar (explicar y examinar) conocimientos que tienen una vigencia limitada, hoy tienen la difícil tarea de ayudar a aprender de manera autónoma en esta sociedad de cambios vertiginosos. 
Las TICs se han convertido en un eje transversal de toda acción formativa donde casi siempre tendrán una triple función:

- como instrumento facilitador de los procesos de aprendizaje (fuente de información, canal de comunicación entre formadores y estudiantes, recurso didáctico),

- como herramienta en el proceso de la información y

- como contenido implícito de aprendizaje (los estudiantes al utilizar las TICs aprenden sobre ellas y potencian sus competencias digitales).

Para integrar y utilizar con eficiencia y eficacia las TICs, el docente necesita una buena formación técnica sobre el manejo de las herramientas y una formación didáctica que le proporcione un "buen saber hacer pedagógico con las TICs". Y si bien no podemos ir al ritmo de los cambios tecnológicos, tampoco podemos estar de espaldas a ellos. Generalmente, la flexibilidad tecnológica se enfrenta a la rigidez académica e institucional que escapa a veces a los propios profesores y centros de estudios. Algunas posturas de rechazo de los docentes en el uso de las TICs abren una brecha generacional que dificulta la comunicación estudiante - docente perjudicando toda pretensión educativa.

Las esperanzas suscitadas por las tecnologías de la información digital pierden consistencia mientras no se consiga integrarlas de verdad en los planes de estudios y la pedagogía.

La amplitud de la problemática educativa presupone la existencia de un personal docente formado y al corriente de las innovaciones tecnológicas, científicas y epistemológicas relacionadas con cada disciplina y con los procesos educativos propiamente dichos. La formación de los docentes debe, por consiguiente, trascender la adquisición de una competencia disciplinaria. Tienen que formar parte de ella tanto el aprendizaje de las nuevas tecnologías como una reflexión sobre los medios para lograr la motivación y dedicación de los estudiantes. El nuevo papel del profesor como asesor, guía, orientador frente a los recursos digitales y las tecnologías, se une aquí, a la vez, en un aprendizaje mutuo con el estudiante, porque para todos siempre hay algo nuevo que aprender. Ayudar al alumno a construir su conocimiento, a buscarlo, a utilizar nuevos soportes para el aprendizaje y la enseñanza, a autoevaluarse mientras que aprendemos con ellos.

Las TICs están ofreciendo nuevos espacios de aprendizajes, espacios en la red que "saltan los muros del aula" donde el alumno puede seguir procesos de aprendizaje desde su casa, con contenidos de apoyo a tareas académicas, o para generar lugares de encuentro extraescolares.

Se supone que con la incorporación de las nuevas tecnologías, cada sociedad estará mejor armada para hacer frente a las rápidas mutaciones que caracterizan al 
mundo contemporáneo. Los jóvenes están llamados a desempeñar un papel fundamental en este ámbito, ya que suelen hallarse a la vanguardia de la utilización de las nuevas tecnologías. Hoy hablamos de nativos digitales y de inmigrantes digitales. Los jóvenes que nacieron entre 1980-1990 son los llamados generación X o $M,{ }^{4}$ son los hiperconectados de la WEB 2.0. Los nacidos desde el año 2000 hasta la actualidad constituyen la Generación Z. ${ }^{5}$ Como usuarios de Internet se convierten no sólo en receptores y poseedores de esta nueva cultura de la era de la información, sino también en sus protagonistas. Son los prosumidores de Internet (Piscitelli A., 2007), consumidores y productores, usuarios y protagonistas de esta nueva democracia digital que integran las comunidades virtuales y redes sociales. Por ejemplo la práctica de los blogs que cualquiera puede publicar en línea, se extienden y transforman gracias a la voluntad y acción de internautas individuales. Así son los ciudadanos de siglo XXI.

La diversidad de las modalidades de acceso al conocimiento constituye una de las características más importantes de las sociedades del aprendizaje. Las clases de geografía no pueden estar ajenas a este cambio. La reducción de la brecha digital tendrá que efectuarse a menudo recurriendo a soluciones mixtas combinando "antiguas" con nuevas tecnologías y construyendo auténticas sociedades del conocimiento.

El campus virtual es un espacio de trabajo utilizando Internet como plataforma de aprendizaje. Es diseñado para lograr una mayor interacción entre alumnos, docentes, autoridades y con toda la comunidad educativa, para exponer a los alumnos y docentes a nuevas tecnologías como las aplicaciones y servicios de la Web 2.0. Además, todos los procesos son públicos, transparentes, ubicuos y adaptables. Un verdadero ejemplo de gestión del conocimiento y de práctica social donde enseñamos y aprendemos juntos. El campus virtual genera docentes y alumnos más flexibles y abiertos; preparar a los alumnos para manejarse en un entorno de cambio acelerado y de innovación. Edgar Morín afirmó que enfrentar la incertidumbre es un factor importante para la educación del futuro. El aula virtual o la clase virtual reproduce lo que hacemos los docentes cada vez que entramos en el aula: presentamos contenidos, explicamos, enseñamos a desentrañar conceptos complejos, ejemplificamos, contextualizamos, jerarquizamos lecturas, se proponen actividades, material de estudio, trabajos prácticos, autoevaluaciónes, preguntas. En una clase virtual, donde no hay contacto cara a cara entre docente y alumnos, la presentación debe incluir expresiones

4 La Generación X, influenciados por la cadena de televisión MTV, son también conocidos como Generación M o Generación MTV.

5 La Generación Z son las personas que están acostumbradas a las interacciones sociales mediante medios virtuales y menos acostumbrados a las interacciones sociales reales, las cuales en la práctica representan un desafío para muchos. A la generación $\mathrm{Z}$ también se le llama la generación silenciosa, IGen y generación net. 
comunicativas que den calidez. También es interesante trabajar con Sistemas de Posicionamiento Global (GPS), realidad virtual y videos explicativos que se pueden bajar de YouTube. Todas ellas son herramientas didácticas muy actuales.

La sociedad del nuevo milenio cambia inexorablemente. Cambian las formas de trabajar, divertirnos, estudiar, relacionarnos, aprender mediados por las nuevas tocologías. Son las tecnologías de la información y la comunicación que están hasta modificando nuestra forma de pensar ${ }^{6}$. Pero lamentablemente, la nueva sociedad del conocimiento se mundializa de una manera profundamente desigual. En la nueva sociedad que emerge, la educación representa, más que en otras épocas, la única llave de entrada al futuro. Se necesitan individuos adaptables y críticos frente a las propuestas de un mundo diferente. Personas capaces de comprender y organizar la complejidad de la información, que utilicen y generen nuevas formas de comunicación para asumir las nuevas opciones planeadas por la realidad en el marco de la pluralidad conceptual.

\section{La Geografía y las TICs}

La Geografía trata temas de gran actualidad que por su dinámica requiere información actualizada y de distintas fuentes. La búsqueda con criterio en Internet es una buena solución. Se puede acceder a estadísticas, datos censales, fotos, videos, opiniones, bibliografía o información específica. Internet ofrece un material muy rico para elaborar distintas propuestas didácticas. Una simple pregunta de los alumnos se puede transformar en una propuesta de trabajo: buscar en Internet, en distintas fuentes (institucionales, gubernamentales, académicas y periodísticas), verificando la confiabilidad y validez de la información obtenida; es una gran fuente de productos: videos, textos, hipertextos, entrevistas radiales, programas de televisión, muestras fotográficas, recorridos virtuales a museos, juegos didácticos, etc. Las TICs permiten apropiarse de toda esa información, seleccionarla y trabajarla para producir algo nuevo que, además, puede ser publicado de forma virtual y ser compartido, ya sea a través de un video en YouTube, o de alguna red social. Las TICs facilitan en los alumnos la apropiación de los contenidos y la participación en la construcción de conocimiento, al sentirse involucrados.

La Web es una importante fuente de información pero no siempre se tiene en escuelas y en el hogar buena conexión de red. Por eso es importante organizar las secuencias didácticas incluyendo actividades que se puedan realizar sin conexión. Esto significa dejar preparado el material en las PC para disponer cuando sea necesario.

Las nuevas tecnologías de la Información y la Comunicación (TICs) en Geografía incluyen: 
- Atlas digitales, mapas electrónicos, planos con buscadores de calles.

- Imágenes satelitales: permiten observar la Tierra desde el espacio generando enorme cantidad de información.

- Sistemas globales de navegación por satélite: el sistema más conocido es el GPS, pero no es el único. Estos sistemas satelitales permiten conocer las coordenadas de ubicación y aplicarlo a diversas cuestiones. Tanto para indicar la trayectoria que se debe seguir en el automóvil como para monitorear los hábitos de fauna en peligro.

- Mapas satelitales: las imágenes satelitales permiten no sólo observar la Tierra sino también medir y cuantificar propiedades del territorio observado. Así se puede calcular la temperatura de la superficie de la Tierra, medir la concentración de clorofila en la superficie del mar, calcular las precipitaciones acumuladas, entre otras y generar mapas.

- Información geográfica o geoinformación: se encuentra íntimamente relacionada con las imágenes satelitales y los sistemas de navegación por satélite.

- Cuando observamos nuestra posición en el receptor GPS lo hacemos generalmente sobre un mapa, sobre el cual podemos calcular a qué distancia estamos, por ejemplo, de una estación de servicio. Cuando miramos una imagen del Servicio Meteorológico para ver el estado del tiempo, necesitamos superponer los límites de los países para podernos ubicar en el territorio.

- Modelos en tres dimensiones: a partir de información captada por los satélites mediante distintas técnicas, se generan modelos digitales. Estos modelos nos permiten, mediante la aplicación de técnicas de modelado gráfico por computadora, visualizar y navegar las imágenes satelitales en tres dimensiones.

- Sistemas de Información Geográfica (SIG): se aplican principalmente en el análisis y resolución de problemáticas en la que interviene la relación entre la sociedad y el espacio geográfico. Toda actividad social o hecho natural se localiza sobre la superficie terrestre formando parte del espacio geográfico. A través de un SIG podemos introducir datos geográficos que permiten modelizar la realidad, representar el presente, reconstruir el pasado y proyectar el futuro en función de los diferentes escenarios. Los SIG resuelven problemas reales y ayudan a tomar decisiones individuales o colectivas produciendo Información Geográfica a partir del análisis espacial. Cuando se utiliza un SIG se apela a la Geografía pues se pone al espacio geográfico en el centro.

Esta realidad nos obliga a analizar la mejor forma de integrar las nuevas tecnologías como herramientas fundamentales a las propuestas de enseñanza.

Las imágenes satelitales y los SIG propician en los alumnos el desarrollo de inteligencia espacial potenciando habilidades intelectuales. Favorecen el aprendizaje y 
por lo tanto se presentan como una potente y eficaz herramienta didáctica. La observación y el análisis de las imágenes enriquecen las conceptualizaciones privilegiando el desarrollo de otras capacidades y de otras formas de conocer a partir de lo visual. Como recurso didáctico, complementan al mapa y a otros documentos transmitiendo una nueva visión del espacio geográfico. Los datos extraídos de estas imágenes proveen de información valiosa que enriquece el campo de la investigación así como la toma de decisiones con mayor calidad de información debido a su naturaleza multidisciplinaria.

El uso de imágenes satelitales y SIG en la escuela enriquece las propuestas de enseñanza pues moviliza contenidos previos, los resignifica y articula con los nuevos saberes.

El valor de las nuevas tecnologías en la enseñanza resulta indiscutido y su incorporación en las prácticas docentes se hace indispensable a la hora de generar propuestas innovadoras orientadas a mejorar los aprendizajes.

\section{El Taller}

Ante los cambios tecnológicos y en educación, decidimos organizar en el marco del Instituto Panamericano de Geografía e Historia, un taller con una propuesta de capacitación teórico-práctico, desarrollado virtualmente, cuyo eje lo constituyeron las Tecnologías de la Información y la Comunicación desde la mirada particular de la Geografía. Pensamos que los mejores destinatarios serían los docentes de nivel medio de América.

El objetivo principal de la capacitación fue otorgar a los docentes herramientas didácticas que les permitan generar y desarrollar prácticas de enseñanza innovadoras a partir del uso de información espacial. Las sociedades actuales plantean nuevas formas de comunicación, de construcción de conocimiento y de convivencia. Esta realidad nos obliga, como docentes, a buscar y analizar la mejor forma de integrar las nuevas tecnologías a las propuestas de enseñanza y aprendizaje para que estas sean potenciadoras y facilitadoras. Con el Taller promovimos el uso de las Tecnologías de la Comunicación e Información Geográfica.

Otro de los objetivos fue revalorizar y resignificar contenidos curriculares de Geografía con nuevas propuestas y enfoques didácticos. Los contenidos desarrollados incluyeron a la Geografía como ciencia social, el concepto de Espacio geográfico y de Geografía automatizada, las TICs y la Información Geográfica en el proceso de enseñanza-aprendizaje de la Geografía, la teledetección y el uso de las imágenes satelitales y, por supuesto los SIG y la cartografía digital con la incorporación del Google Earth y Google Maps como recursos didácticos. 
En forma transversal y en un todo de acuerdo con la Agenda Panamericana 20102020, se propusieron actividades relacionadas con el cambio climático, el ordenamiento territorial, los desastres naturales y con el manejo del agua. Así como estudios de caso de diferentes espacios americanos.

Durante el año 2013, se realizó una convocatoria para los Estados Miembros del IPGH contactando con los representantes de cada país quienes se encargaron de replicar la convocatoria.

El Instituto Geográfico Nacional de Argentina se encargó de la realización de la ficha de inscripción, de la distribución de folletos y de recibir los pedidos. Por razones operativas y para asegurar un seguimiento adecuado de las actividades encomendadas, el curso funcionó con un mínimo de 20 participantes y un máximo de 40 .

En los primeros días, se recibieron 711 inscripciones. Más de la mitad correspondían a docentes de México, aunque también de El Salvador, Belice, República Dominicana, Costa Rica, Perú y Argentina. Para alcanzar los cupos fijados se respetó el orden de inscripción.

El Departamento Técnico del IGN de Argentina, desarrolló el aula virtual o plataforma de e-learning. Además del diseño y puesta en funcionamiento del aula-taller, los técnicos del IGN se encargaron, en todo momento, del mantenimiento y funcionamiento de la plataforma. En simultáneo se desarrolló el proyecto pedagógico con el asesoramiento y la participación de la licenciada Liliana Russian.

El desarrollo de todos los contenidos y el material de estudio estuvieron a cargo de la responsable del Taller con el asesoramiento de la Academia Nacional de Geografía. También se trabajó la sugerencia de bibliografía de lectura obligatoria y complementaria y la selección de imágenes satelitales de los diferentes encuentros, así como los trabajos en los que participaron los tutores. Se propusieron actividades relacionadas con el cambio climático y los desastres naturales. Así como estudios de caso de diferentes espacios americanos.

El material de estudio estuvo a disposición para que los cursantes lo descargasen en sus computadoras y pudieran leerlo sin necesidad de estar conectados. Cada cursante organizó las clases y las actividades según sus tiempos, dentro del término establecido en la planificación y midiendo sus conocimientos en un proceso de autoaprendizaje con evaluaciones on-line.

El Taller se desarrolló en 16 encuentros semanales desde el 3 de junio al 29 de septiembre. Todos los lunes se incorporaba un encuentro y se corregían las actividades del anterior de cada alumno.

También se mantuvieron diariamente las tutorías que estuvieron presentes para responder a las consultas y a los aspectos relevantes que hacían al desarrollo del Taller. El foro de discusión permitió participar en debates y potenciar los intercambios entre colegas de distintas instituciones y de distintos países, además de consultas sobre las actividades. 


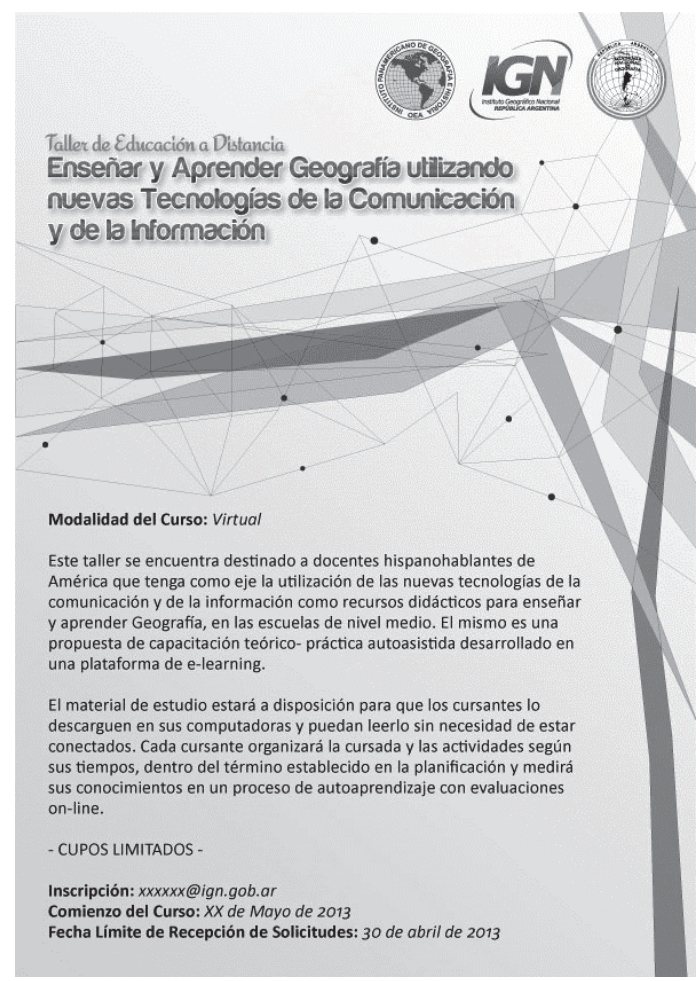

Figura 1. Poster de promoción del Taller.

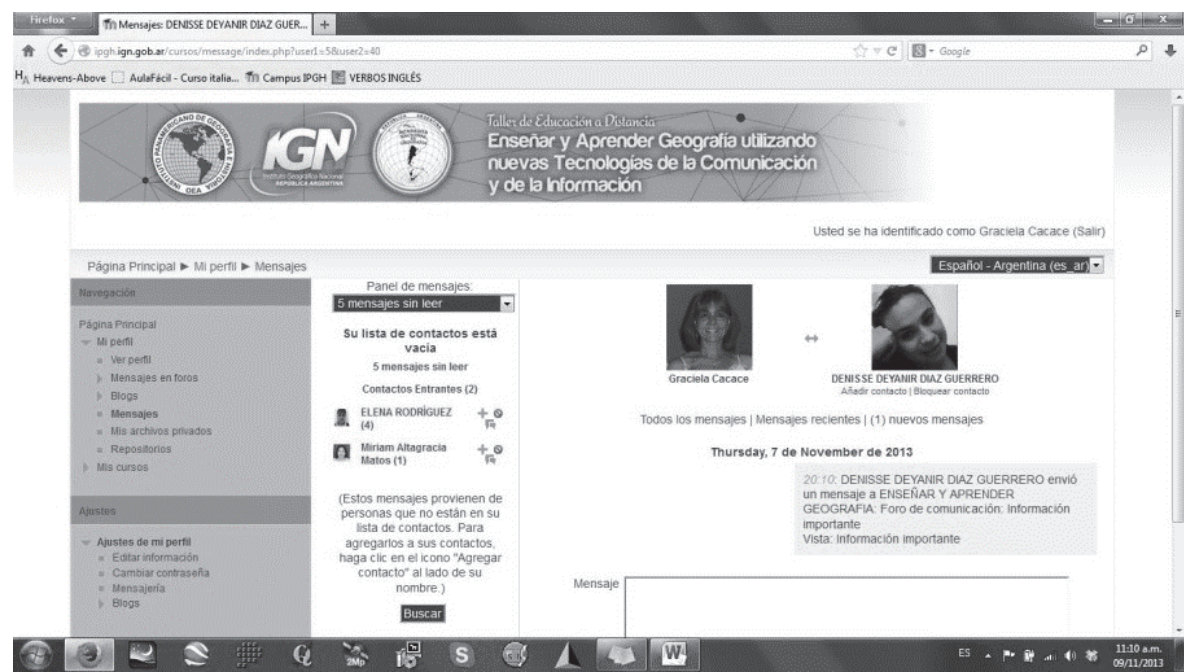

Figura 2. Captura de una de las pantallas del Taller virtual. 


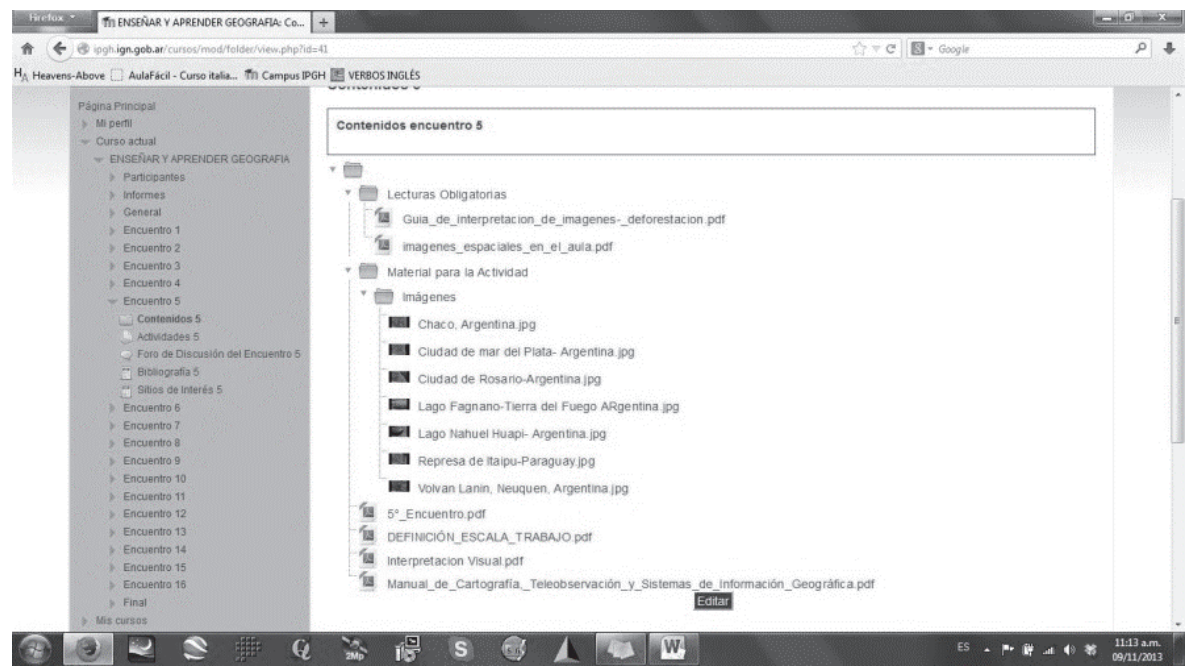

Figura 3. Captura de la pantalla con el desarrollo de los contenidos de una unidad.

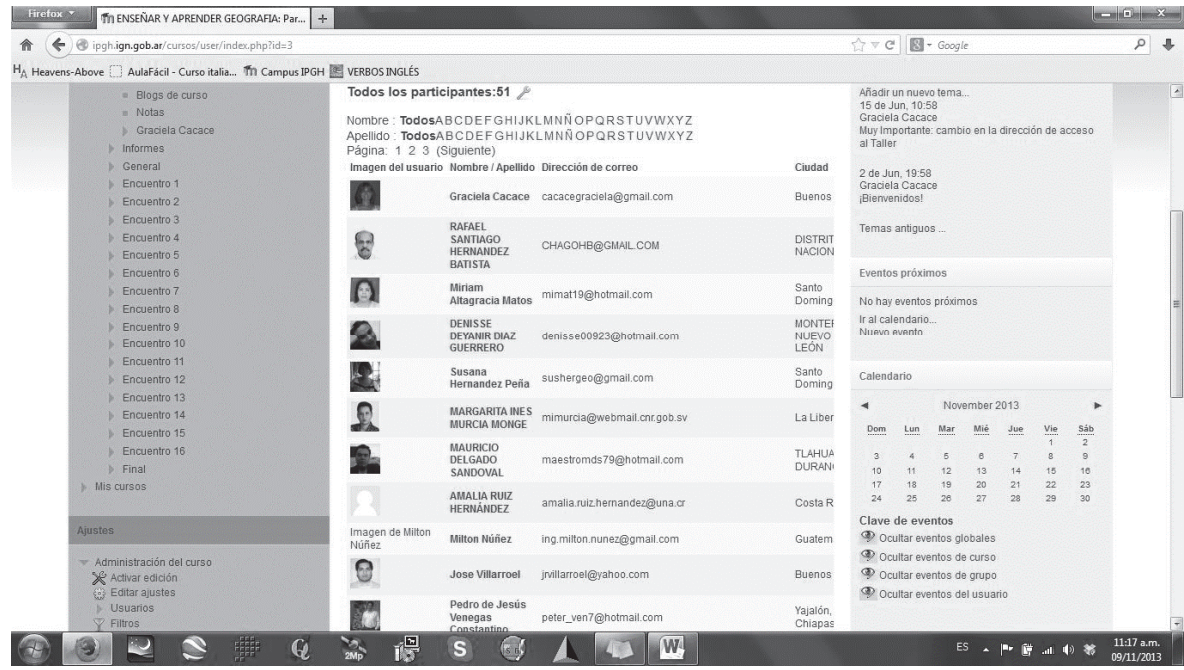

Figura 4. Captura de la pantalla con el listado de los alumnos participantes.

Los requisitos para la acreditación del Taller incluían la lectura del material, la participación en el foro, la entrega de todas las actividades que figuraban en el cronograma como obligatorias y la entrega de un proyecto final. 


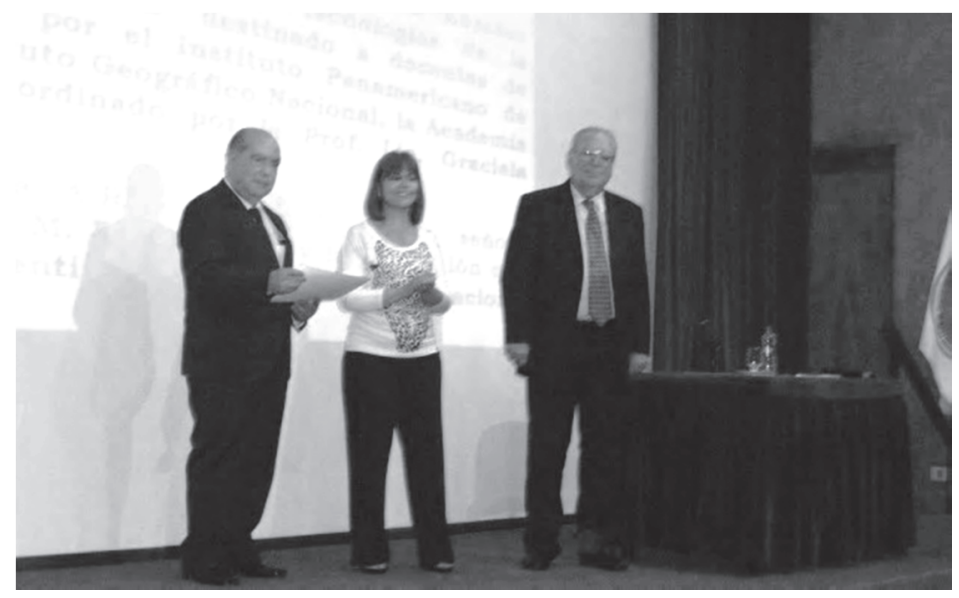

Figura 5. Acto de entrega de diplomas el 27 de noviembre de 2013 en el IGN, Argentina. De izquierda a derecha: profesor Cornejo, Presidente de la Academia de Geografia; profesor Pena, Presidente del IPGH y profesora Cacace.

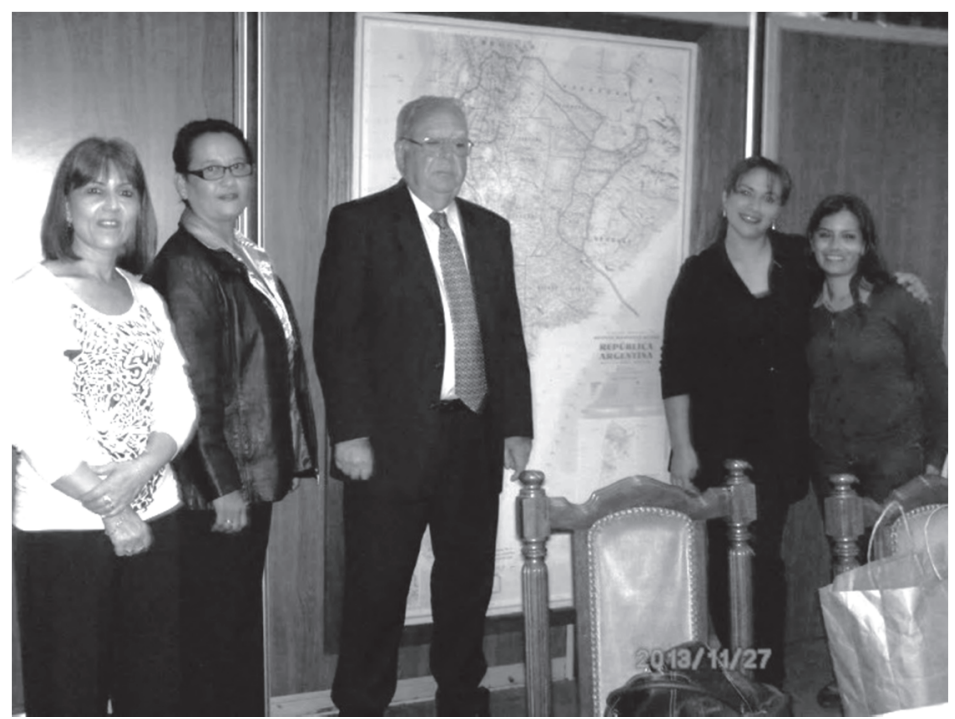

Figura 6. Encuentro en la Academia Nacional de Geografía, con las ganadoras de los trabajos seleccionados. De izquiera a derecha: Graciela Cacace, Margarita Inés Murcia Monge (El Salvador), Héctor Pena, Denisse Deyanir Díaz Guerrero (México) y Josefina González. 
De los trabajos finales, se seleccionó la mejor propuesta didáctica para el aula. Los ganadores fueron invitados a participar en una reunión en Buenos Aires, el 27 de noviembre de 2013 donde presentaron sus trabajos y como formador de formadores son los encargados de replicar el Taller en su país transformándose a su vez en tutor nacional.

Trabajos seleccionados:

- "Propuesta de curso de capacitación de la enseñanza de la Geografía utilizando las Tecnologías de la Información”, profesora Denisse Deyanir Díaz Guerrero, Monterrey, Nuevo León, México.

- "Educación Ambiental y el deterioro de la Cuenca Hidrográfica del río Jiboa, en El Salvador”, profesora Margarita Inés Murcia Monge, San Salvador, El Salvador.

Con los trabajos finales (que fueron de gran calidad) de todos los docentes participantes, se editó un DVD que fue entregado a todas las Secciones Nacionales del IPGH y a entidades educativas que lo solicitaron con el fin de motivar a los docentes en la utilización de las nuevas Tecnologías de la Comunicación y de la Información Geográfica.

Los resultados alcanzados son más que satisfactorios, se evidenció en los foros, en la entrega de las actividades y en las consultas. Los docentes/estudiantes trabajan en condiciones muy diferentes unos de otros. Hay cursantes pertenecientes a escuelas agropecuarias de México y docentes universitarios de Belice o República Dominicana. En muchos países centroamericanos no existe la materia Geografía en la currícula de la escuela secundaria, sin embargo, los docentes están interesados en enseñarla y en aplicar nuevas tecnologías, hubo un interesante debate al respecto. La comunicación fue fluida entre los propios docentes-estudiantes con intercambio de materiales, propuestas, consejos, colaboraciones en línea. Se logró un ambiente cálido de mucho trabajo y satisfacciones; se evidenció la necesidad de realizar tallerescursos para docentes. También se realizó una Encuesta con resultados muy satisfactorios respecto del desarrollo del mismo.

Después de más de un año de mucho trabajo, el Taller de educación a distancia, finalizó con la satisfacción, no sólo por la tarea cumplida sino por lo generado en cada participante que ahora tienen la responsabilidad de aplicar los conocimientos en sus clases. La educación va de la mano de las oportunidades que les brindamos a nuestros alumnos para aprender. Ésta fue una buena oportunidad de aprendizaje para todos. 


\section{Taller de educación a distancia "Enseñar y aprender Geografía utilizando nuevas cecnologías de la comunicación y de la información"}

Fecha de inicio: 3 de junio de 2013

Fecha de cierre: 29 de septiembre de 2013

Acto de entrega de diplomas / certificados: 27 de noviembre de 2013

Coordinadora general del proyecto: profesora-licenciada Graciela Cacace

Asesoramiento pedagógico: profesora-licenciada María Liliana Russian

Tutores: profesora Gimena Conforti, profesor José Rómulo Villarroel Valencia, profesora Josefina González.

Apoyo informático y logístico (IGN): señorita Mónica Beatriz Gallardo, licenciado Eduardo Bordon, técnico suplente Tomás Marcote, licenciado Emiliano Fernández Lascano, diseñadora gráfica Danila Marotta Capdevila.

Instituciones participantes:

Instituto Panamericano de Geografía e Historia

Sección Argentina:

Instituto Geográfico Nacional, República Argentina

Academia Nacional de Geografía, República Argentina

\section{Agradecimientos}

Agrimensor Sergio Cimbaro, profesor Antonio Cornejo, profesor Héctor Pena; sin el apoyo de ellos, no hubiéramos podido desarrollar el Taller con éxito.

\section{Bibliografía}

Araya, F.R., "Perspectivas en la enseñanza de la geografía escolar y universitaria", en Delgado Mahecha, O. y Cristancho Garrido, H. (eds.), Globalización y territorio: reflexiones geográficas en América Latina, Universidad Nacional de Colombia, Bogotá, pp. 341-359, 2009.

Baxendale, C., "Geografía, organización del territorio y Sistemas de Información Geográfica”, en Buzai, G. (ed.), Geografia y Sistemas de Información Geográfica. Aspectos conceptuales y aplicaciones, GESIG-UNLU, Universidad Nacional de Luján, Buenos Aires, pp. 37-49, 2010a.

_ ciplinares en las prácticas de ordenamiento territorial", Fronteras, vol. 9, núm. 9, pp. 25-31, 2010b.

Bunge, M., La Ciencia. Su método y su filosofía, Siglo Veintiuno, Buenos Aires, 1981. 
Buzai, G., Geografia Global, Buenos Aires, Argentina, 1999.

—, La exploración Geodigital, Buenos Aires, Argentina, 2000.

— - Sistemas de Información Geográfica (SIG) y cartografía temática. Métodos y técnicas para el trabajo en el aula, Buenos Aires, Argentina, 2008.

—_, "Análisis Espacial con Sistemas de Información Geográfica: Sus cinco conceptos fundamentales", en Buzai, G.D. (ed.), Geografia y Sistemas de Información Geográfica. Aspectos conceptuales y aplicaciones, GESIG-Universidad Nacional de Luján, Luján, pp. 163-195, 2010.

—, Análisis socioespacial con Sistemas de Información Geográfica, Buenos Aires, Argentina, 2da. edición, 2011.

Buzai, G.; Baxendale, C., Perspectivas para la enseñanza de los Sistemas de Información Geográfica (SIG) en la educación polimodal, Consudec (Parte I: N॰833:42, Parte II: N834:40 y Parte III: N835:42), 1998.

- Análisis Socioespacial con Sistemas de Información Geográfica, Buenos Aires, Argentina, 2006.

Brunner, J.J., Internet y educación ¿La próxima revolución?, Fondo de Cultura Económica, Santiago, 2002.

Castells, M., La era de la información: economía, sociedad y cultura. Vol. 1: La sociedad red, Alianza Editorial, Madrid, 1997.

Comisión Nacional de Actividades Espaciales, CONAE, Programa 2Mp.

Cruz, M.R., "El Sistema de Información Geográfica como herramienta de disección y síntesis desde la perspectiva lógico-metodológica del proceso de investigación", Anuario de la División Geografía 2007-2008, Departamento de Ciencias Sociales, Universidad Nacional de Luján, Luján, pp. 299-309, 2008.

Chorley, R., Handling Geographic Information. Report of the Comite of Enquiry chaired by Lord Chorley, Department of Environment, London, 1987.

Chiozza, E.; y Carballo, C.; Introducción a la Geografía, Editorial de la Universidad Nacional de Quilmes, 2006.

Chuvieco, Emilio, Fundamentos de teledetección espacial, Ediciones Rialp, Madrid, 2000.

Delgado Mahecha, O., Debates sobre el espacio en la geografia contemporánea, Universidad Nacional de Colombia, Bogotá, 2003.

Dobson, J.E., "Reply to Comments on 'Automated Geography", The Professional Geographer, vol. 45, no. 4, pp. 431-439, 1983.

Gould, P., "Pensamientos sobre la Geografía", GeoCrítica, núm. 68, pp. 1-39, 1987. Haggett, P., The Spirit of Quantitative Geography. Geographical Analysis, núm. 40, pp. 226-228, 2008.

Klimovsky, G., Las desventuras del conocimiento cientifico. Una introducción a la epistemología, AZ ediciones, Buenos Aires, 1994. 
Miraglia, Marina, Manual de Cartografía, Teleobservación y Sistemas de Información Geográfica, Laboratorio de Sistemas de Información Geográfica, Universidad Nacional de General Sarmiento, Buenos Aires, Argentina, 2010.

Moreno Jiménez, A., "En torno a los conceptos de equidad, justicia e igualdad espacial", Huellas, núm. 11, pp. 133-142, 2006.

Morin, E., Los siete saberes necesarios para la educación del futuro, UNESCO, 1999.

Naveh, Z.; Lieberman, S., Landscape Ecology: Theory and Applications, SpringerVerlag, New York, 1984.

Ostuni, J., "Metodología en Geografía. Investigación en el Departamento e Instituto de Geografía", Anales de la Academia Nacional de Geografia, núm. 25, pp. 89104, Buenos Aires, 2001.

Piaget, J., Psicología y epistemología, Emecé Editores, Buenos Aires, 1972.

República Argentina, Acceso universal a la alfabetización digital. Políticas, problemas y desafios en el contexto argentino, Serie: La educación en debate, Documentos de la DiNIECE 5, Ministerio de Educación, Ciencia y Tecnología, Dirección Nacional de Información y Evaluación de la Calidad Educativa, 2007.

Soja, E., Postmodern Geographies: the reassertion of space in critical social theory, Verso, London, 1989.

Taylor, P.J., "Editorial Comment: GKS", Polish Geography Quarterly, no. 9, pp. 211-212, 1990.

Vilá Valentí, J., Introducción al estudio teórico de la Geografia, Ariel, Barcelona, 1983. 